\title{
3D NUMERICAL SIMULATION OF LAMINAR FLOW AND CONJUGATE HEAT TRANSFER THROUGH FABRIC
}

\author{
Guocheng Zhu, Dana Kremenakova, Yan Wang, Jiri Militky, Rajesh Mishra, Jakub Wiener
}

Department of material engineering, Technical University of Liberec, Studentská 1402/2, Liberec, Czech Republic, Tel: +420 776485167 , Email: zgc100100@hotmail.com

\begin{abstract}
:
The air flow and conjugate heat transfer through the fabric was investigated numerically. The objective of this paper is to study the thermal insulation of fabrics under heat convection or the heat loss of human body under different conditions (fabric structure and contact conditions between the human skin and the fabric). The numerical simulations were performed in laminar flow regime at constant skin temperature $(310 \mathrm{~K})$ and constant air flow temperature $(273 \mathrm{~K})$ at a speed of $5 \mathrm{~m} / \mathrm{s}$. Some important parameters such as heat flux through the fabrics, heat transfer coefficient, and Nusselt number were evaluated. The results showed that the heat loss from human body (the heat transfer coefficient) was smallest or the thermal insulation of fabric was highest when the fabric had no pores and no contact with the human skin, the heat loss from human body (the heat transfer coefficient) was highest when the fabric had pores and the air flow penetrated through the fabric.
\end{abstract}

\section{Keywords:}

Numerical simulation, fluid flow, heat transfer, heat convection, heat transfer coefficient

\section{Introduction}

Textile as clothing is an integral part of human beings and plays the primary role of protecting the body against unsuitable environments by avoiding mechanical, thermal, and chemical damages and maintaining thermal balance, which means the clothing needs to be sensitive enough to the environment and generate a reasonable thermal microenvironment around the body to help it deal with the external weather conditions. The exchange of heat follows a distinct phenomena of simultaneous conduction, convection, and radiation. Heat transfer through conduction and radiation has been well understood and documented [1-6]. However, convective heat transfer through the fabric is difficult to model as there are no exact solutions for porous material under heat convection as well as the limited research work in this area $[7,8]$. The main problem faced in heat convection is the calculation of heat transfer coefficients or the Nusselt number.

The equation of heat transfer coefficient is given by

$$
h=\frac{q}{\Delta T}
$$

or

$$
h=\frac{N u \cdot \lambda}{x}
$$

The general equation of Nusselt number is given by

$$
N u=C \operatorname{Re}^{m} \operatorname{Pr}^{n}
$$

where $h$ is heat transfer coefficient, $q$ is heat flux, $\Delta T$ is temperature difference, $\lambda$ is thermal conductivity, $x$ is thickness of sample, $\mathrm{Nu}$ is the Nusselt number, $R e$ is the Reynolds number, $P r$ is Prandtl number, and $C, m$, and $n$ are constants. However, these solutions are valid only for a specific set of conditions. So for every new situation, a new set of empirical coefficients has to be designed [9].

Beithou [10] studied the effect of the porosity of the porous medium on the Nusselt number for natural convection and reported that with the increase in the porosity, there is a linear increase in the Nusselt number. Hatch [11] confirmed that fabric structural features, not component fibers, are the most important controllers of thermal dissipation. Moreover, heat transfer is highly related to fabric thickness, bulk density, and the air volume fraction. On the other hand, numerical method has been widely used in every area due to its reliable accuracy and flexibility for both realistic and ideal conditions, and more detailed information. Bhattacharjee [8] studied the heat transfer coefficient of fabric under natural and force heat convection by numerical simulation. He found that the values from numerical simulation had a good agreement with the experimental values; however, the fabrics in their numerical simulation were taken as flat plate without pores.

Therefore, in this work, numerical simulation is applied to investigate the local temperature distributions, local heat flux distributions, local/average heat transfer coefficients, and local Nusselt numbers of fabrics taken as plate and porous material under conductive and convective heat transfer. 


\section{Nomenclature}

\begin{tabular}{|c|c|c|c|}
\hline C & Constant, (1) & $T_{0}$ & Air temperature at inlet, $(\mathrm{K})$ \\
\hline$H$ & Enthalpy $\left(\mathrm{J} \cdot \mathrm{kg}^{-1}\right)$ & $T_{\mathrm{s}}$ & Temperature of solid, (K) \\
\hline$h$ & heat transfer coefficient $\left(\mathrm{W} \cdot \mathrm{m}^{-2} \cdot \mathrm{K}^{-1}\right)$ & $T_{\mathrm{f}}$ & Temperature of fluid, (K) \\
\hline$h x$ & $\begin{array}{l}\text { Local heat transfer coefficient(LHTC) } \\
\qquad\left(\mathrm{W} \cdot \mathrm{m}^{-2} \cdot \mathrm{K}^{-1}\right)\end{array}$ & $T_{\text {skin }}$ & Temperature of skin, $(\mathrm{K})$ \\
\hline$k$ & Heat capacity ratio (1) & $T_{\text {air }}$ & Air temperature, $(\mathrm{K})$ \\
\hline$m, n$ & Power constants (1) & $\Delta T$ & Temperature difference, $(\mathrm{K})$ \\
\hline Ma & Mach number (1) & $u_{0}$ & Inlet velocity, $\left(\mathrm{m} \cdot \mathrm{s}^{-1}\right)$ \\
\hline $\mathrm{Nu}$ & Nusselt number (1) & $U$ & Velocity vector, $\left(\mathrm{m} \cdot \mathrm{s}^{-1}\right)$ \\
\hline Nux & Local Nusselt number (LNN) (1) & $x$ & Thickness or Distance, (m) \\
\hline$p$ & Pressure $(\mathrm{Pa})$ & $\Lambda$ & Thermal conductivity, $\left(\mathrm{W} \cdot \mathrm{m}^{-1} \cdot \mathrm{K}^{-1}\right)$ \\
\hline$p t$ & Total pressure $(\mathrm{Pa})$ & $\lambda_{a}$ & Thermal conductivity of air, $\left(\mathrm{W} \cdot \mathrm{m}^{-1} \cdot \mathrm{K}^{-1}\right)$ \\
\hline$p b$ & Back pressure $(\mathrm{Pa})$ & $\lambda_{\mathrm{f}}$ & Thermal conductivity of fluid, $\left(\mathrm{W} \cdot \mathrm{m}^{-1} \cdot \mathrm{K}^{-1}\right)$ \\
\hline$\Delta p$ & Pressure drop $(\mathrm{Pa})$ & $\lambda_{\mathrm{s}}$ & Thermal conductivity of solid, $\left(\mathrm{W} \cdot \mathrm{m}^{-1} \cdot \mathrm{K}^{-1}\right)$ \\
\hline $\operatorname{Pr}$ & Prandtl number (1) & $\rho$ & Density, $\left(\mathrm{kg} \cdot \mathrm{m}^{-3}\right)$ \\
\hline$q x$ & Heat flux $\left(\mathrm{W} \cdot \mathrm{m}^{-2}\right)$ & $\mu$ & Dynamic viscosity, $\left(\mathrm{Pa} \cdot \mathrm{s}\right.$ or $\left.\mathrm{kg} \cdot \mathrm{m}^{-1} \cdot \mathrm{s}^{-1}\right)$ \\
\hline$R$ & Gas constant $\left(\mathrm{J} \cdot \mathrm{kg}^{-1} \cdot \mathrm{K}^{-1}\right)$ & $\mathrm{v}$ & Kinematic viscosity, $\left(\mathrm{m}^{2} \cdot \mathrm{s}\right)$ \\
\hline $\operatorname{Re}$ & Reynolds number (1) & $\alpha$ & Thermal diffusivity, $\left(\mathrm{m}^{2} \cdot \mathrm{s}\right)$ \\
\hline $\operatorname{Rex}$ & Local Reynolds number (1) & & \\
\hline
\end{tabular}

\section{Physical model, boundary conditions, governing equations and numerical method}

In real conditions, the human-clothing-environment system under heat convection is very complicated, depending upon the temperature of the environment, the clothing structures, and the contacting area between human body and cloth. This is especially true for the clothing structures, which are variable in terms of patterns, pore size, porosity, thickness, and so on. Due to the difficulties in generating complex structures by a software program, thereby, the structure of fabrics was simplified to flat plate and flat porous plate, which somehow could reflect the heat transfer mechanism through fabrics under heat convection. Therefore, the simplified 3-D geometric model consists of flat polyester fabric and air flow, which is shown in Figure 1. In order to save the computation time, the dimensions of polyester fabric were $30 \mathrm{~mm} \times 4 \mathrm{~mm} \times 0.8 \mathrm{~mm}$ in length $(x$ direction), width ( $y$ direction), and height ( $z$ direction), and the dimensions of air flow above fabric were $30 \mathrm{~mm} \times 4 \mathrm{~mm} \times$ $4 \mathrm{~mm}$ in length, width, and height, the dimensions of air flow below fabric were $30 \mathrm{~mm} \times 4 \mathrm{~mm} \times 2 \mathrm{~mm}$ in length, width, and height. Therefore, the coordinates of geometric domain were $X$ $(0,30), Y(0,4)$, and $Z(-2,4.8)$. The mesh quality of geometric models was evaluated by two parameters, which were minimum orthogonal quality and maximum aspect ratio. The minimum orthogonal qualities of simulation 1 and 2 were over 0.99 and the maximum aspect ratios were around 7.56 , which mean the mesh qualities were very high. The minimum orthogonal quality and maximum aspect ratio of simulation 3 were 0.28 and 15.6, which mean the mesh quality was also good enough. The materials used were air as fluid and polyester as solid. The properties of air and polyester are given in Table 1.

In order to simulate different conditions of human-clothingenvironment, three kinds of simulation were carried out.

Simulation 1: the fabric was taken as a plate and contacted with human body

Simulation 2: the fabric was taken as a plate having an air gap between human body and fabric, and the air flow below fabric was stagnant

Table 1. Properties of air and polyester

\begin{tabular}{|c|c|c|c|c|}
\hline Material & $\begin{array}{l}\text { Density } \\
\left(\mathbf{k g} \cdot \mathbf{m}^{-3}\right)\end{array}$ & $\begin{array}{l}\text { Specific heat } \\
\left(\mathrm{J} \cdot \mathbf{k g}^{-1} \cdot \mathrm{K}^{-1}\right)\end{array}$ & $\begin{array}{c}\text { Thermal conductivity }\left(\mathrm{W} \cdot \mathrm{m}^{-}\right. \\
\left.1 \cdot \mathrm{K}^{-1}\right)\end{array}$ & $\begin{array}{l}\text { Viscosity } \\
\left(\mathrm{kg} \cdot \mathrm{m}^{-1} \cdot \mathrm{s}^{-1}\right)\end{array}$ \\
\hline Air & Incompressible-ideal-gas & 1006.43 & 0.0242 & $1.7894 \times 10^{-5}$ \\
\hline Polyester & 1416 & 1300 & 0.12 & - \\
\hline
\end{tabular}




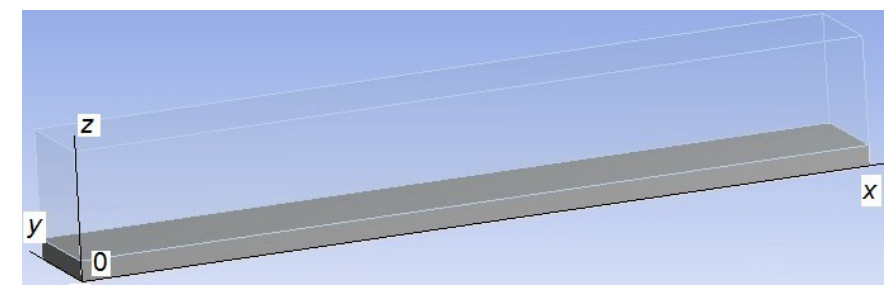

Simulation 3: the fabric was taken as a porous plate having an air gap between human body and fabric, and the air flow below the fabric can freely move. The pore's diameter was $1 \mathrm{~mm}$, and the distance between two pores was $2 \mathrm{~mm}$.

According to the objective of simulation, the boundary conditions were given: the temperature contacting with human

Figure 1a. Geometric model of simulation 1

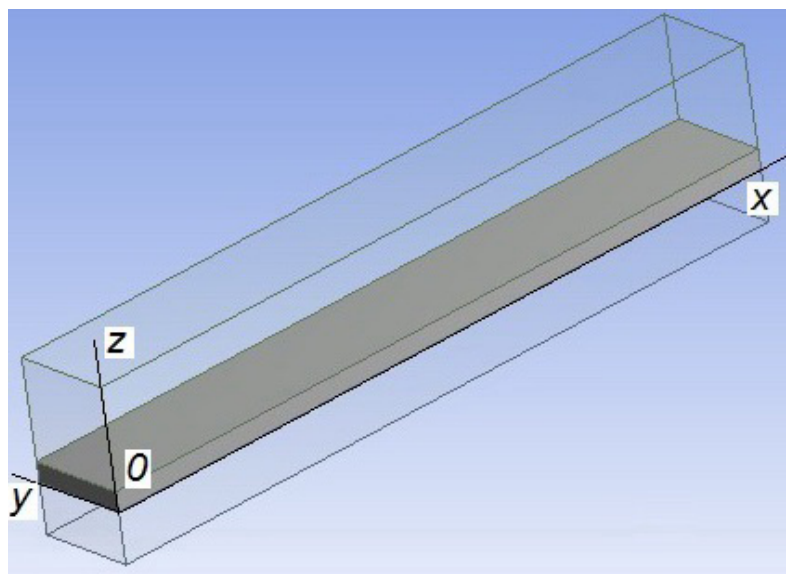

Figure 1b. Geometric model of simulation 2

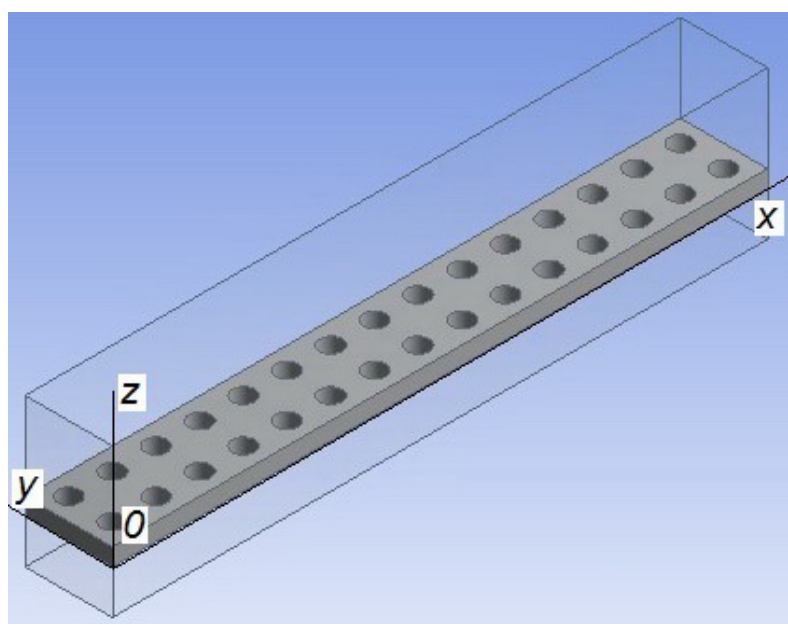

Figure 1c. Geometric model of simulation 3

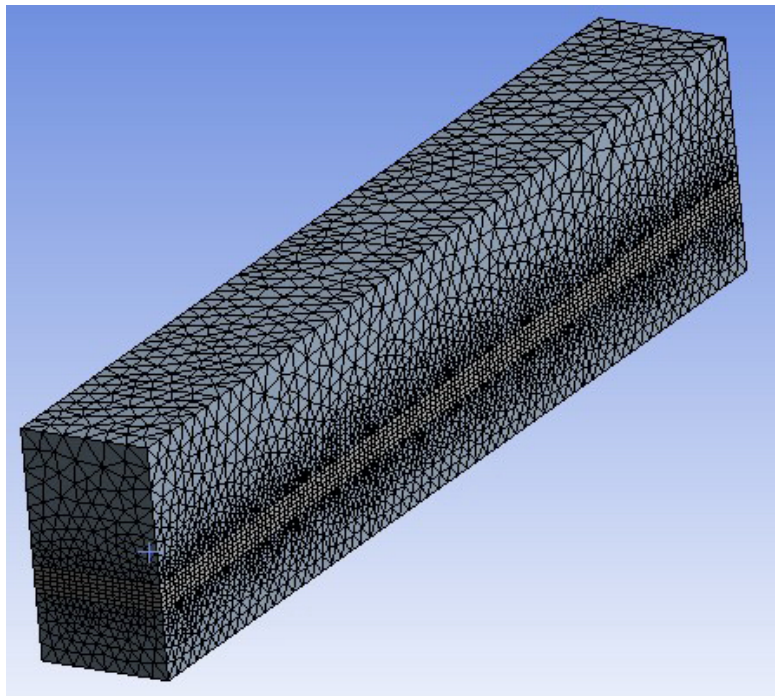

Figure 1d. Computational grid of simulation 3 body was $310 \mathrm{~K}$ and the temperature of air flow above the fabric was $273 \mathrm{~K}$ at a speed of $(5 \mathrm{~m} / \mathrm{s})$. From the above known information, the following useful information for simulation can be obtained:

The Mach number

$$
M_{\mathrm{a}}=u_{0} / \sqrt{k R T_{0}}
$$

The total pressure

$$
\frac{p_{\mathrm{t}}}{p_{\mathrm{b}}}=\left[1+\frac{k-1}{2} M_{\mathrm{a}}^{2}\right]^{k /(k-1)}
$$

The pressure drop

$$
\Delta p=p_{\mathrm{t}}-p_{\mathrm{b}}
$$

The governing equations for calculation are given as follows. The heat conduction equation for the solid part is:

$$
\nabla \cdot\left(\lambda_{\mathrm{s}} \nabla T_{\mathrm{s}}\right)=0
$$

The mass, momentum, and energy equations as well as the ideal gas equation of state are given by

$$
\begin{aligned}
& \nabla \cdot(\rho U)=0 \\
& \nabla \cdot(\rho U U)=-\nabla p+\nabla \cdot\left(\mu\left(\nabla U-\frac{2}{3} \nabla \cdot U I\right)\right) \\
& \nabla \cdot(\rho U H)=\nabla \cdot\left(\lambda_{f} \nabla T_{f}\right) \\
& p=\rho R T
\end{aligned}
$$

where $I$ is the unit tensor.

The partial differential equations governing the problem are reduced to a system of algebraic equations using finite volume procedure. The discretization of the convective and diffusive fluxes across the control surfaces is modeled using the QUICK scheme and the pressure-velocity coupling is handled with the SIMPLE method. The convergence criterion is that the residual variations of the mass, momentum, and energy conservation equations become less than $10^{-7}$. 


\section{Results and discussions}

\subsection{Temperature distribution in xz-plane}

The temperature distributions (TD) and heat flux distributions (HFD) in $x z$-plane at $y=2 \mathrm{~mm}$ are given in Figure 2. The temperature gradually decreased from the bottom of geometric model (human skin) to the top of air flow, the temperature decreased along the cross-section of fabric and the temperature of air increased in the near region of fabric surface, which indicated that the heat conduction and heat convection were coupled numerically. In addition, the temperatures of fabric and air close to the air flow inlet (left side of figures) were lower than the temperatures close to the air flow outlet due to the cooling effect of cold air flow. And the temperature distribution of simulation 3 was quite different with the other simulations due to the existence of pores where the cold air flow can go through.

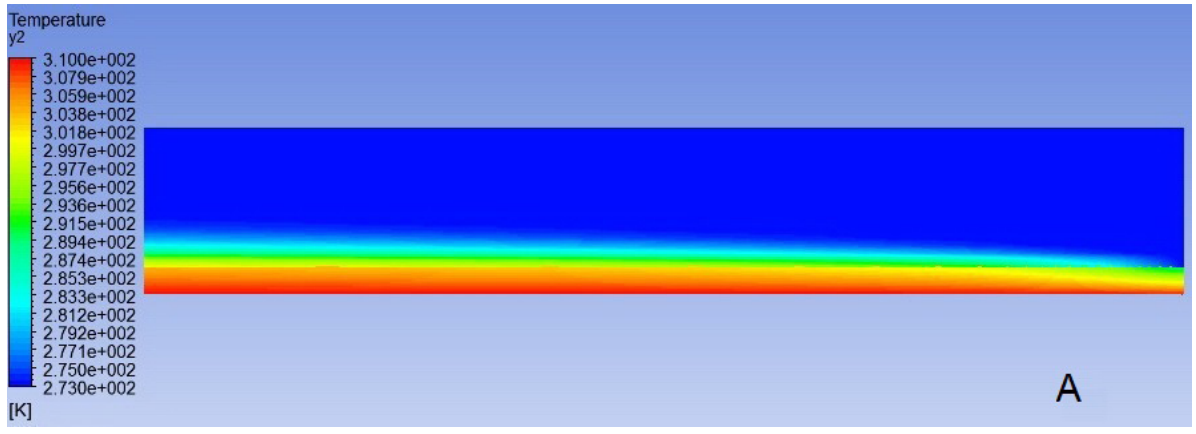

Figure 2a.Temperature distribution of simulation 1 in xz-plane

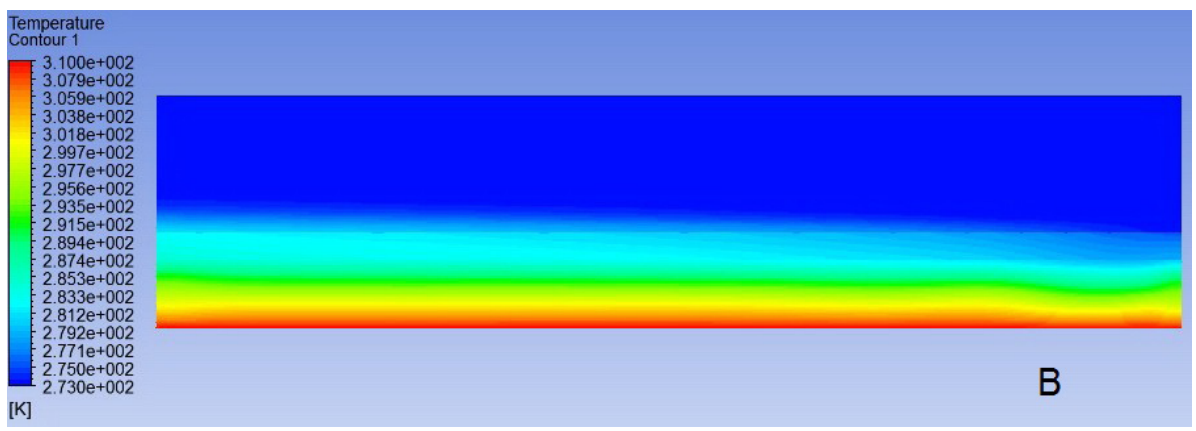

Figure 2b.Temperature distribution of simulation 2 in xz-plane

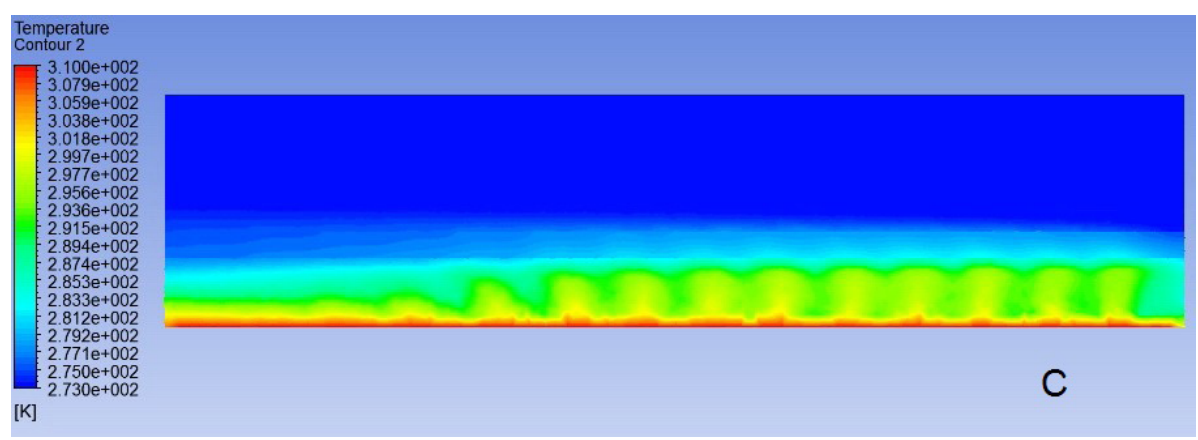

Figure 2c. Temperature distribution of simulation 3 in xz-plane

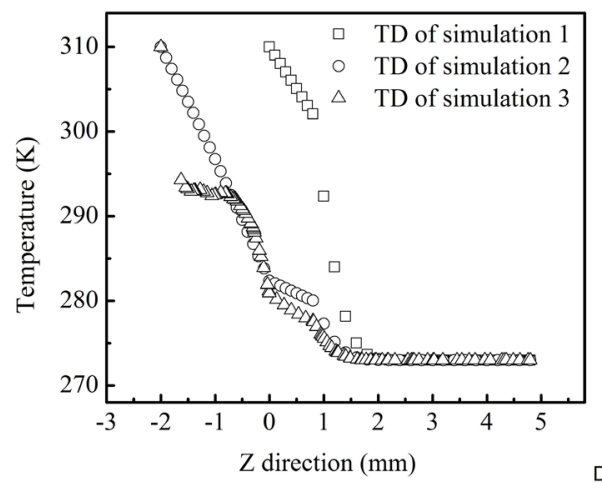

Figure 2d. Temperature distributions of simulations in xz-plane 
The temperature distributions in $x z$-plane at $y=2$ were compared in Figure 2D. For simulations 1 and 2, the temperatures were decreasing gradually in the near the region of bottom (skin), but for simulation 3 , the temperature was decreasing dramatically at the beginning, which is due to the air flow moving much faster than the heat transfer rate by conduction. In the region of air flow above the fabric, the temperature distributions were almost the same.

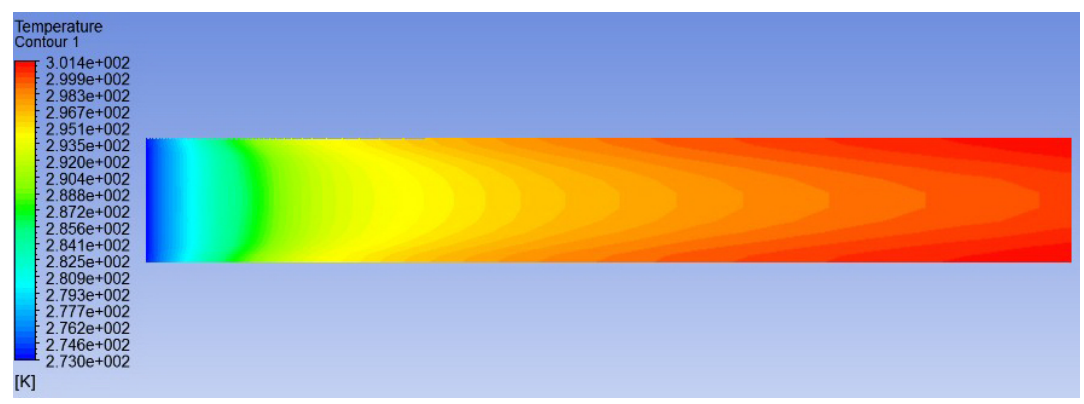

Figure 3a. Temperature distribution of simulation 1 on the upper

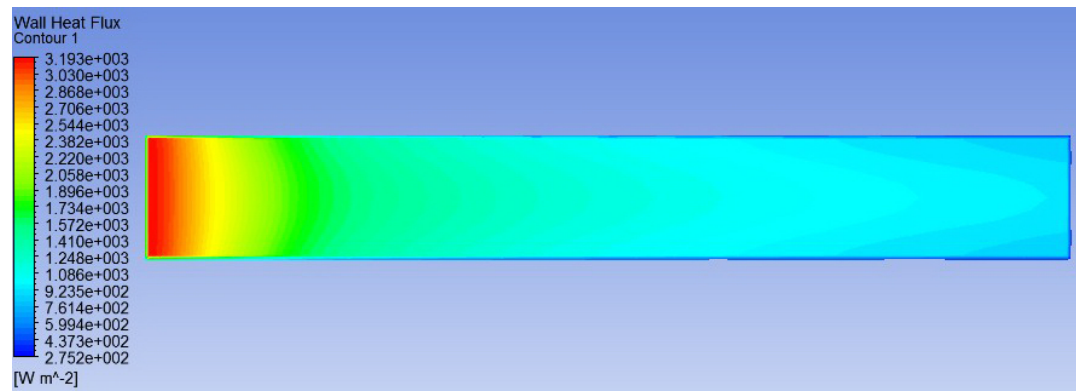

Figure 3b. Heat flux distribution of simulation 1 through fabri

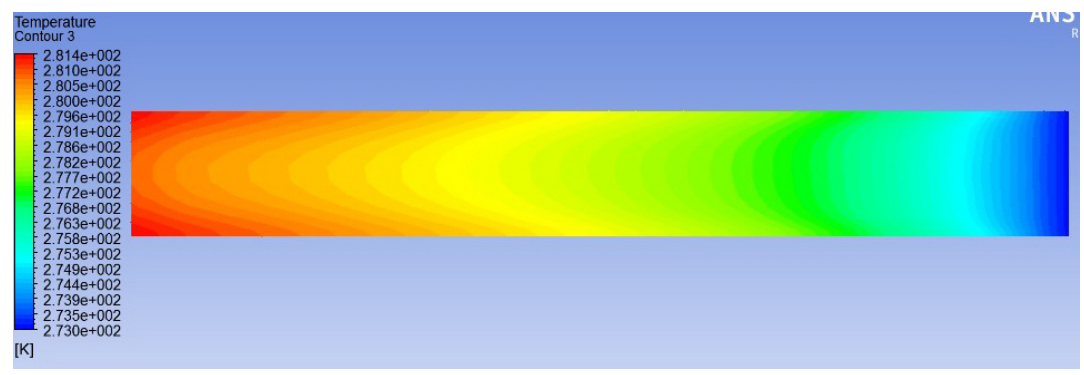

Figure 3c. Temperature distribution of simulation 2 on the upper

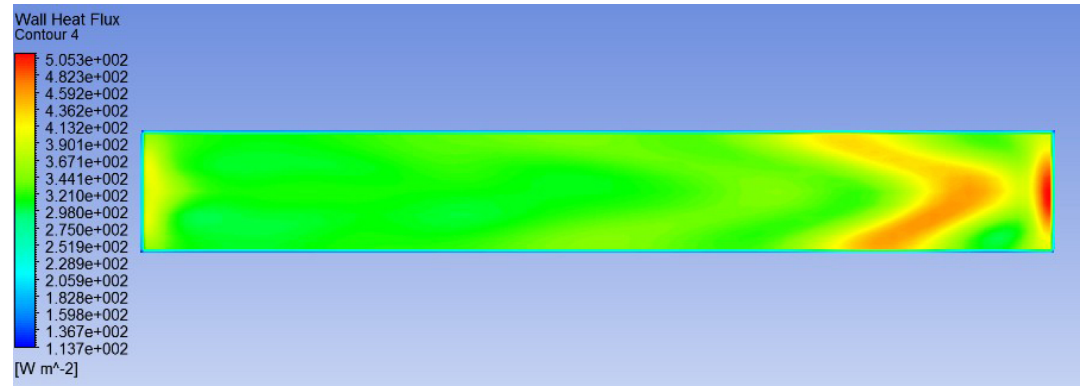

Figure 3d. Heat flux distribution of simulation 2 through fabric

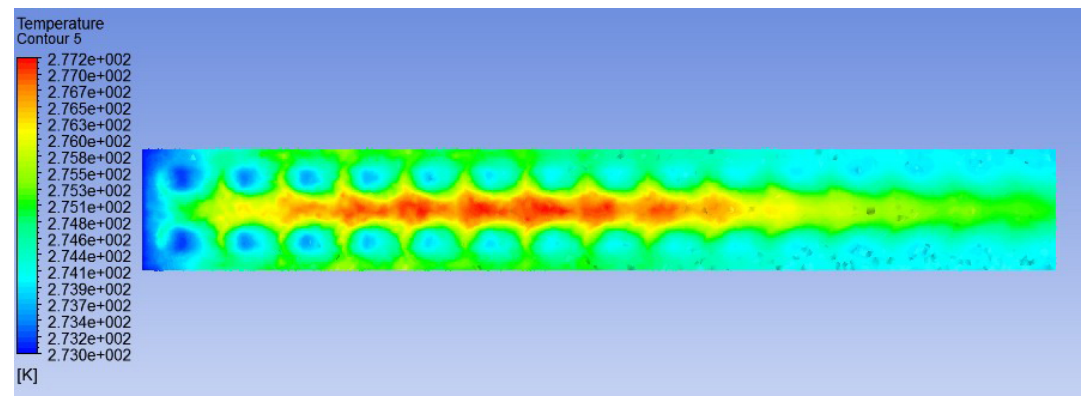

Figure 3e.Temperature distribution of simulation 3 on the upper 


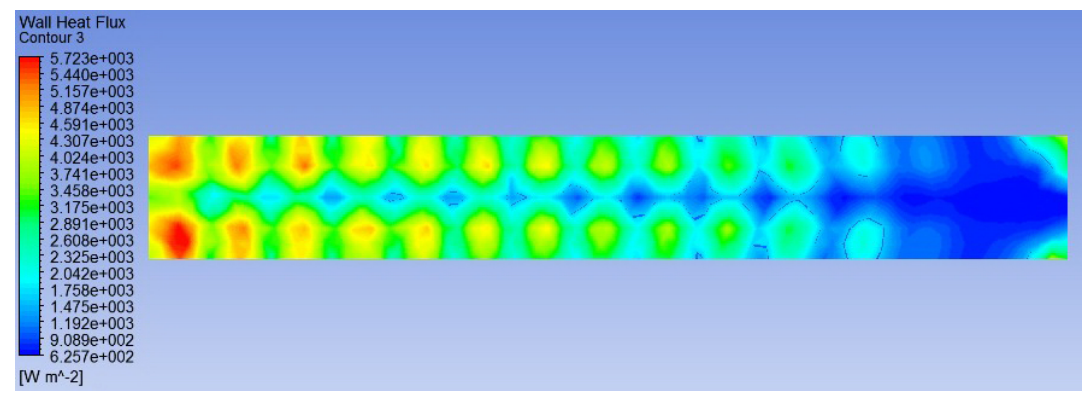

Figure 3f. Heat flux distribution of simulation 3 through fabric

\subsection{Temperature distribution and heat flux distribution on the fabric surface}

The temperature distributions and heat flux distributions on the fabric surface are given in Figure 3. The temperatures of fabric surfaces from the air inlet to air outlet kept increasing due to the lower temperature of moving air. In contrast, the heat fluxes kept decreasing. For simulation 3 , the temperature distribution and heat flux distribution had the same trend with simulations 1 and 2 , but the local temperature and heat flux were quite different due to the difference of fabric structure and the air flow motion. And the air flow motion of simulation 3 is given in Figure 4.

A clearer comparison of temperature and heat flux distributions on fabric surface is given in Figure 5 . The temperatures of simulations 1 and 2 increased as the distance increased since the cold air flow was cooling the fabric surface, as well as heating by the fabric surface at the same time. Therefore, the cooling effect of air flow was reduced as the distance increased, and then the temperature was higher as the distance increased. For simulation 3 , the temperature and heat flux distributions were different at $y$ $=2$ (the middle line of fabric surface) and $y=3$ (the middle line of pores on the fabric surface) due to the air flow motion. The temperature increased first, and then decreased at $y=2$ since the air flow below the fabric had more intense cooling at the outlet (as shown in Figure 4). The temperature had a cyclical fluctuations at $y=3$ since the cold air flow went through the regular solid-pore structure of the fabric. With respect to the heat flux distribution, the higher temperature was corresponding to the lower heat flux.

\subsection{Comparison of heat transfer coefficient and Nusselt number}

In order to obtain the heat transfer coefficient of fabric under heat convection, the temperature gradient and heat flux are needed according to equation (2), and the local heat transfer coefficient is given by

$$
h_{x}=\frac{q_{x}}{\left(T_{\text {air }}-T_{\text {skin }}\right)}
$$

The local Nusselt number is given by

$$
N u_{x}=h_{x} x / \lambda_{a}
$$

Substituting equation (12) into equation (13), then the local Nusselt number is given by

$$
N u_{x}=\frac{h_{x} x}{\lambda_{a}}=\frac{q_{x}}{T_{\text {skin }}-T_{\text {air }}} \frac{x}{\lambda_{a}}
$$

On the other hand, the Nusselt number is one function of Reynolds number (the ratio of inertial force to viscous force) and Prandtl number (the ratio of molecular diffusivity of momentum to molecular diffusivity of heat), which can be expressed generally by equation (1). But for particular situations, the constants of $C, m$, and $n$ are always different. And for flat plate in laminar flow, the Nusselt number can be obtained by[9]

$$
\begin{array}{r}
N u_{x}=0.332 \operatorname{Re}_{x}^{0.5} \operatorname{Pr}^{1 / 3} \\
\text { where } \operatorname{Re}_{x}=\rho u x / \mu \text {, and } \operatorname{Pr}_{x}=v / \alpha
\end{array}
$$

The heat transfer coefficient and Nusselt number are given in Figure 6. Normally, the relationship between Reynolds number

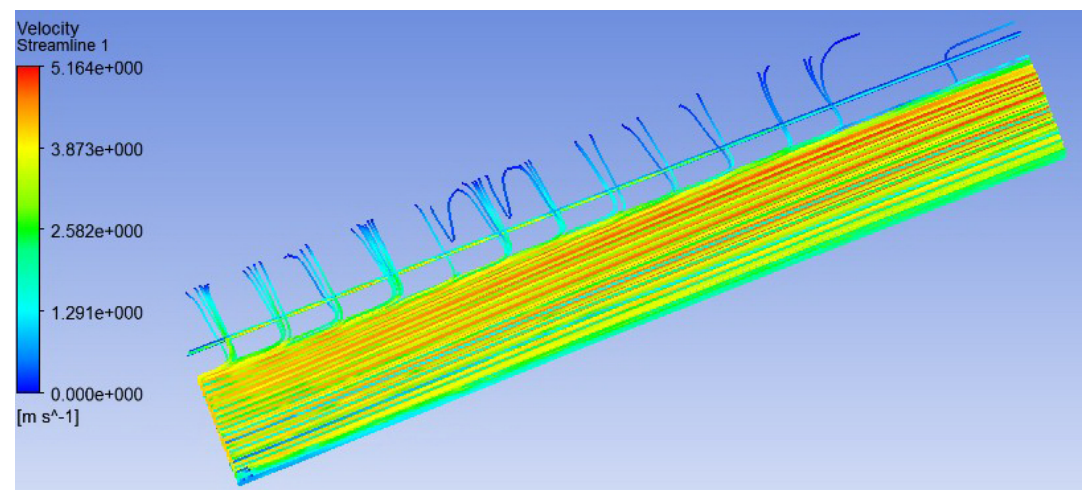

Figure 4. Velocity profile of simulation 3 


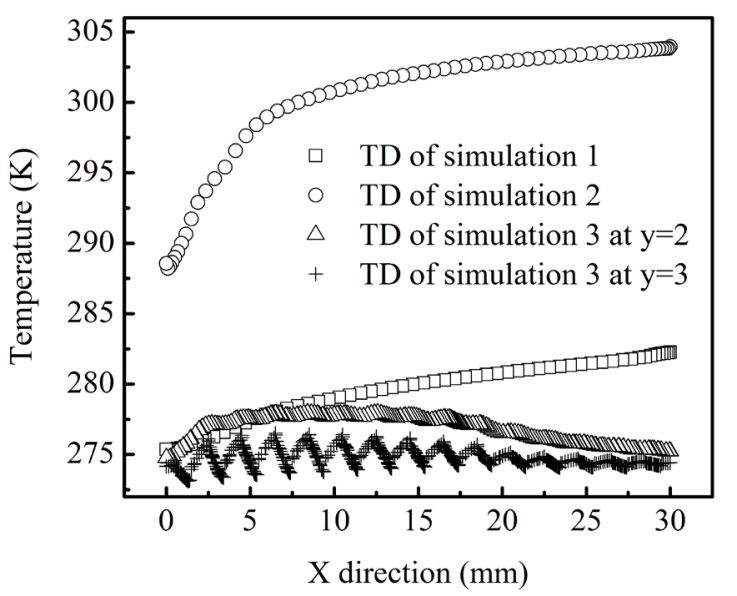

Figure $\mathbf{5 a}$. Temperature distributions of simulations in $x y$-plane

and Nusselt number should be presented, but in this paper, the distance is given instead of Reynolds number since the Reynolds number is one function of distance, and the aim of this paper is to investigate the distribution of Nusselt number on the fabric surface. The heat transfer coefficients and Nusselt numbers from simulation 1 had a very good agreement with the results from equation (15) (as shown in figure 6) since this model was derived from the geometry model of simulation 1 . It also indicated that the simulation process and results were correct and reliable. But the heat transfer coefficients and Nusselt numbers from simulation 2 were much lower than the results from model due to the very low thermal conductivity of air gap, which slowed down the heat transfer rate. The heat transfer coefficients of simulation 3 at $y=2$ had a general decreasing trend and had a small fluctuations around the values from model. The fluctuation of results is due to the different heat transfer rates of heat conduction through fabric and the heat convection by air flow. The heat transfer coefficients of simulation 3 at $y=3$ had a similar trend with simulation 3 at $y$ $=2$, but the values were much higher than the values from the

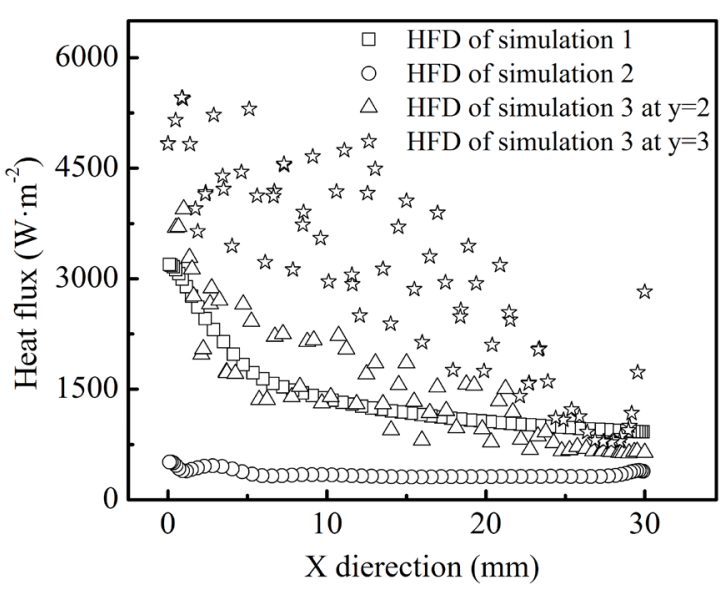

Figure 5b. Heat flux distributions of simulations through fabric

model, which indicates that the existence of pores increases the heat transfer rate. The Nusselt numbers of simulation 3 at $y=2$ were fluctuating around the values from the model, but the Nusselt numbers of simulation 3 at $y=3$ were fluctuating and much higher than the results from the model, which means the heat transfer by convection was much higher than the heat transfer by conduction.

In addition, the average heat fluxes through the fabrics were obtained by area-weight average method. There were 1346.9 $\mathrm{W} \cdot \mathrm{m}^{-2}, 342.3 \mathrm{~W} \cdot \mathrm{m}^{-2}$, and $2520.4 \mathrm{~W} \cdot \mathrm{m}^{-2}$ for simulation 1 , simulation 2 , and simulation 3 , respectively. Then, the average heat transfer coefficients of simulations were $36.4 \mathrm{~W} \cdot \mathrm{m}^{-2} \cdot \mathrm{K}^{-1}$, $9.25 \mathrm{~W} \cdot \mathrm{m}^{-2} \cdot \mathrm{K}^{-1}$, and $68.12 \mathrm{~W} \cdot \mathrm{m}^{-2} \cdot \mathrm{K}^{-1}$, respectively. Therefore, the thermal insulation of fabric will be much better when there is an air gap between the fabric and the skin. The porosity will have a negative effect on thermal insulation when air flow has motion and penetrates the fabric.

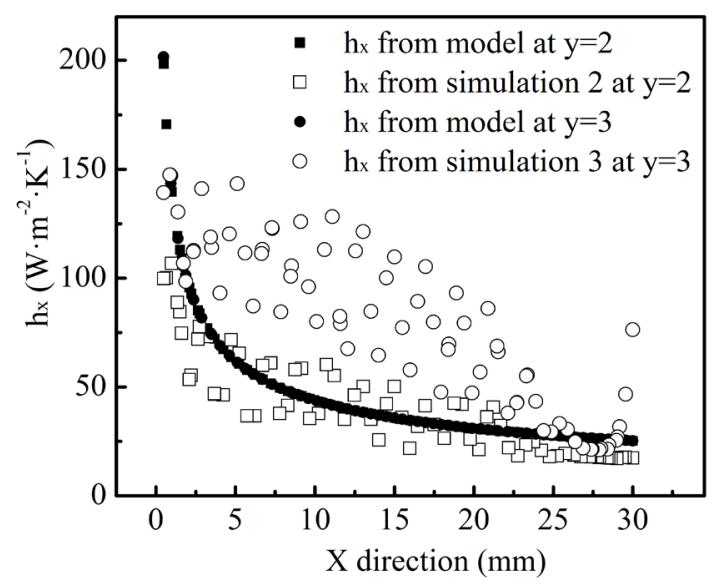

Figure 6b.Comparison of local heat transfer coefficient of model

Figure 6a. Comparison of local heat transfer coefficient of model 


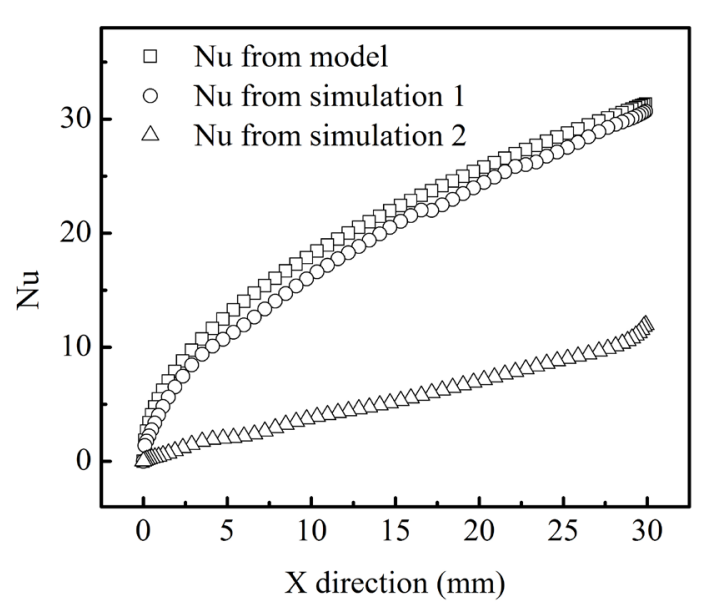

Figure 6c. Comparison of local Nusselt number of model and simul

\section{Conclusions}

The heat transfer coefficient and Nusselt number of fabrics in different conditions under heat convection was investigated numerically in this work, and some conclusions can be drawn based on the results,

(1) The numerical simulation of flow and the conjugate heat transfer through the fabric can be an accurate and reliable method depending upon the good agreement between the simulation results and a well-known analytical model. (2) The stagnant air gap will be helpful for increasing the thermal insulation, but the open-structure pores will have a negative impact on increasing thermal insulation. (3) The local heat transfer coefficients and Nusselt numbers of porous fabrics have a big difference, and the skin would have different thermal conduction at different local areas. In addition, more work is needed to be done in order to investigate the effect of pore size, pore's distribution, the angle between the air flow and the fabric, and the air flow velocity on the thermal insulation of the fabric.

\section{References}

[1] Lee, S. C.; Cunnington, G. R. (2000). Conduction and radiation heat transfer in high-porosity fiber thermal insulation. J Thermophys Heat Tr,14 (2), 121-136.

[2] Mohammadi, M.; Banks-Lee, P.; Ghadimi, P. (2003). Determining effective thermal conductivity of multilayered nonwoven fabrics. Text Res J,73 (9), 802-808.

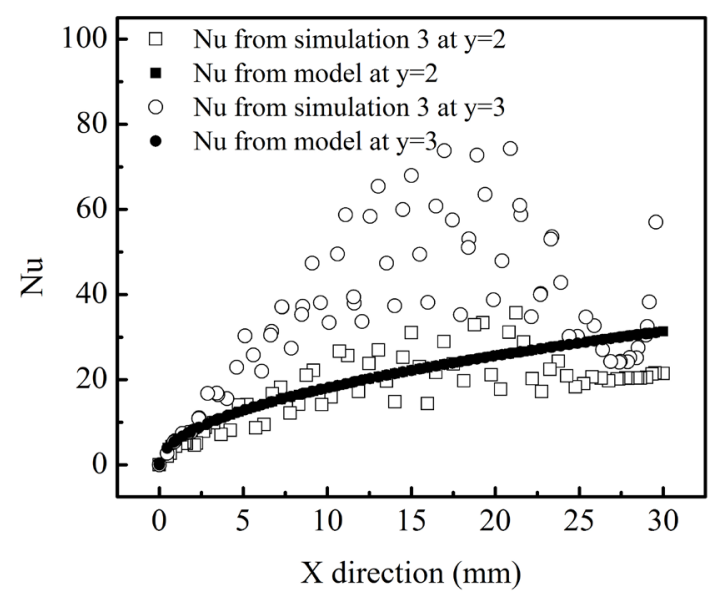

Figure 6 d. Comparison of local Nusselt number of model and simul

[3] Guocheng Zhu; Dana Kremenakova; Yan Wang, et al. (2014). An analysis of effective thermal conductivity of heterogeneous materials. Autex Res J,14 (1), 14-21.

[4] Etemoglu, A. B.; Ulcay, Y.; Can, M., et al. (2009). Mathematical modelling of combined diffusion of heat and mass transfer through fabrics. Fiber Polym, 10 (2), 252-259.

[5] Darvishzadeh, M.; Semnani, D.; Shirani, E., et al. (2012). Improvement Modelling of Heat Transfer by Using Complex Neural Net in Fibrous Structures. Fiber Polym, 13 (4), 542548.

[6] Raeisian, L.; Mansoori, Z.; Hosseini-Abardeh, R., et al. (2013). An Investigation in Structural Parameters of Needle-Punched Nonwoven Fabrics on Their Thermal Insulation Property. Fiber Polym, 14 (10), 1748-1753.

[7] Bhattacharjee, D.; Kothari, V. K. (2008). Measurement of Thermal Resistance of Woven Fabrics in Natural and Forced Convections. Research Journal of Textile and Apparel, 12 (2), 39-49.

[8] Bhattacharjee, D.; Kothari, V. K. (2008). Prediction of thermal resistance of woven fabrics. Part II: Heat transfer in natural and forced convective environments. J Text I,99 (5), 433-449.

[9] Cengel, Y. A., (2003). Heat transfer: A practical approach. (2nd ed). New York, McGraw-Hill.

[10] Beithou, N.; Albayrak, K.; Abdulmajeed, A. (1998). Effects of porosity on the free convection flow of non-Newtonian fluids along a vertical plate embedded in a porous medium. Tr. J. Eng. Environ. Sci.,22, 203-209.

[11] Hatch, K. L.; Woo, S. S.; Barker, R. L., et al. (1990). In Vivo Cutaneous and Perceived Comfort Response to Fabric. Part 1: Thermophysiological Comfort Determinations for Three Experimental Knit Fabrics. Textil. Res. J.,60 (7), 405-412. 